\title{
Identification and characterization of IncRNA AP000253 in occult hepatitis B virus infection
}

\author{
Qingqin Hao ${ }^{1}$, Zheng Wang ${ }^{2}$, Qinghui Wang ${ }^{1}$, Bo Chen ${ }^{1}$, Huizhong Qian ${ }^{1}$, Xiao Liu ${ }^{1}$, Hong Cao², Wei Xia 1*,
} Jian Jiang ${ }^{1 *}$ and Zhonghua Lu ${ }^{2^{*}}$

\begin{abstract}
Background: Recent studies suggest that IncRNAs may play significant roles in the development of hepatitis B virus (HBV) infection. However, as a special stage of HBV infection, the IncRNA expression in occult HBV infection (OBI) remains unclear.
\end{abstract}

Methods: The plasma level of $15 \mathrm{HBV}$ infection-related IncRNAs was initially detected using qRT-PCR in $10 \mathrm{OBI}$ and 10 healthy controls (HCs) in discovery phase. Significantly dysregulated IncRNAs were subsequently validated in another $64 \mathrm{OBI}, 20 \mathrm{HCs}, 31$ chronic hepatitis B (CHB) and 20 asymptomatic HBsAg carriers (ASC). Moreover, the AP000253 expression in liver tissues and its potential biological functions in $\mathrm{HBV}$ infection were further investigate with public transcriptomic data and HBV-expressing cell lines.

Results: Among candidate IncRNAs, the plasma level of AP000253 decreased significantly in OBI, ASC and CHB patients compared to HCs, while no difference was found among OBI, ASC and CHB patients. In liver tissues, similar AP000253 expression was also observed from the GSE83148 dataset, while that in HBV-expressing hepatoma cells was opposite. ROC curve analysis indicated that plasma AP000253 yielded an AUC of 0.73 with $60 \%$ sensitivity and $75 \%$ specificity when differentiating OBI from HCs, but it could not specifically separate the stage of chronic HBV infection. Furthermore, functional experiments suggested that AP000253 could promote HBV transcription and replication in hepatoma cell lines.

Conclusions: AP000253 might be involved in HBV replication, and be served as a potential biomarker for HBV infection. In the setting of blood donations, plasma AP000253 would be more useful to moderately distinguish OBI in HBsAg-negative donors. However, the AP000253 expression in liver tissues and associated molecular mechanism of HBV infection deserve further study in future.

Keywords: Hepatitis B virus, Occult infection, IncRNAs, AP000253, Biomarker

*Correspondence: xiawe25@126.com; jiangjian62@126.com; Lu_z_h1@126.com

${ }^{1}$ Department of Clinical Laboratory, Wuxi Red Cross Blood Center, 109

Xinmin Road, Wuxi 214000, China

${ }^{2}$ Department of Liver Disease, Wuxi No.5 People's Hospital Affiliated

to Jiangnan University, 1215 Guangrui Road, Wuxi 214000, China

\section{Introduction}

As a phase of chronic hepatitis B virus (HBV) infection, occult HBV infection (OBI) is characterized as an absence of serum HBV surface antigen ( $\mathrm{HBsAg}$ ) and the presence of replication-competent HBV DNA in the liver $[1,2]$. The prevalence of OBI varies tremendously across the world and patient populations, with up to $0.5 \%$ in HBsAg-negative blood donors [1]. Although the precise pathogenesis is still unclear, OBI is primarily considered as the combined result of host immune control and different genomic expressions of the virus, leading original author(s) and the source, provide a link to the Creative Commons licence, and indicate if changes were made. The images or other third party material in this article are included in the article's Creative Commons licence, unless indicated otherwise in a credit line to the material. If material is not included in the article's Creative Commons licence and your intended use is not permitted by statutory regulation or exceeds the permitted use, you will need to obtain permission directly from the copyright holder. To view a copy of this licence, visit http://creativecommons.org/licenses/by/4.0/. The Creative Commons Public Domain Dedication waiver (http://creativeco mmons.org/publicdomain/zero/1.0/) applies to the data made available in this article, unless otherwise stated in a credit line to the data. 
to a virological quiescent state $[1,3,4]$. Hence, the blood HBV DNA is usually very low $(<200 \mathrm{IU} / \mathrm{ml})$. Unfortunately, due to limited sensitivity of available commercial assays, viral DNA is always not or intermittently detected at this low load, also known as sampling effect of Poisson distribution [5]. Despite low viral load, OBI can still result in HBV transmission via blood transfusion, maternal and infant, organ transplant and other ways, and HBV reactivation after receiving chemotherapy or other immunosuppressive therapies, and even evolves toward serious liver diseases, such as cirrhosis, liver failure and hepatocellular carcinoma $[1,6,7]$. Therefore, owing to the potential of missed diagnosis and HBV transmission and reactivation, $\mathrm{OBI}$ has recently gained more and more widespread attention worldwide $[8,9]$.

Long noncoding RNAs (lncRNAs), used to be considered as "transcriptional noise", are a class of transcripts longer than 200 nucleotides without protein-coding functions [10]. It is now clearly elucidated that lncRNAs may function as promising regulators of epigenetic, transcriptional and posttranscriptional gene expression, and play significant roles in various biological and pathological processes by interacting with RNA, DNA or protein and closely associated with cancers, immune, inflammatory and infectious diseases especially viral infection $[11,12]$. During infection, in response to viral transcription or replication, infected cells may express viral, cellular or chimeric lncRNAs [12, 13]. Then, these lncRNAs can function diverse effects on the virus-host interaction, and consequently determine the clinical outcome [12, 14]. Up to now, several IncRNA profiles of different stages of chronic HBV infection have been reported [15-19], and functional and mechanism studies further reveal that abnormally expressed lncRNAs might play important roles in the development of HBV infection, such as HULC [19, 20], PCNAP1 [21], HOTTIP [22], lncRNA\#32 [23], HOTAIR [24] and HEIH [19]. However, to our knowledge, unlike miRNAs [25-27], the lncRNA expression in OBI has been not yet investigated.

In the present study, based on our previous microarray data, public GSE83148 dataset and published studies, 15 HBV infection-related lncRNAs were selected as candidates to analyze their plasma expression in OBI and the potential as a biomarker for OBI was evaluated. Furthermore, we further investigated the AP000253 expression in tissues and its biological functions in HBV replication. Overall, these findings might provide a new insight into the screening of OBI and a better understanding of the molecular pathogenesis of $\mathrm{HBV}$ infection.

\section{Materials and methods}

\section{Participants and specimens collection}

This study was conducted in accordance with the Declaration of Helsinki and was approved by the Ethics
Committee of Wuxi Red Cross Blood Center. Written informed consent was obtained from all participants.

Totally, 74 OBI, 20 asymptomatic HBsAg carriers (ASC) and 30 healthy controls (HCs) were enrolled from Wuxi red cross blood center between November 2017 and September 2020. Meanwhile, 31 patients with chronic hepatitis $\mathrm{B}(\mathrm{CHB})$ were consecutively recruited from Wuxi No.5 People's Hospital from May to September 2020. These participants were then randomly divided into the discovery cohorts (10 OBI and $10 \mathrm{HCs})$ and the validation cohorts (64 OBI, $20 \mathrm{ASC}, 31 \mathrm{CHB}$ and 20 $\mathrm{HCs})$. The diagnosis of $\mathrm{CHB}$, ASC and OBI was based on clinical and laboratory results according to the "Guidelines for prevention and treatment of chronic hepatitis B, China (2019)" [28] and "Update of the statements on biology and clinical impact of occult hepatitis b virus infection" [1]. Patients co-infection with hepatitis $\mathrm{A} / \mathrm{C} / \mathrm{D} / \mathrm{E}$ virus, human immunodeficiency virus, syphilis or other serious liver diseases were excluded from this study. Blood samples were collected in ethylene-di-amine-tetraacetic acid containing tubes (BD). After centrifuged at $3000 \mathrm{rpm}$ for $20 \mathrm{~min}$, plasma samples were collected and stored at $-80^{\circ} \mathrm{C}$ for the following research.

\section{RNA extraction and qRT-PCR assay for IncRNA expression}

To search for potential lncRNA biomarkers for OBI, the plasma level of $15 \mathrm{HBV}$ infection-related lncRNAs were preliminarily analyzed by real-time quantitative RT-polymerase chain reaction (qRT-PCR) assay. Of these lncRNAs, 7 lncRNAs were from our previous lncRNA microarray data in liver tissues with HBV infection (AL355102.1, AL160408.1, AC022898.1, G060477, LINC00994, AC092168.1, DHRS) [18], 3 from the public GSE83148 dataset (AP000253, HNF4A-AS1 and HCP5) and 5 from published studies repeatedly reported to be associated with HBV infection (HULC, MALAT1, HOTAIR, HEIH and DREH).

lncRNA quantification was performed as previously described [18]. Briefly, total RNA was extracted with the Trizol reagent (Invitrogen, CA, USA) and the quality was assessed by NanoDrop ND1000 spectrophotometer (Agilent Technologies, CA, USA). Reverse transcription reaction and qPCR were respectively performed using SuperScriptTM III Reverse Transcriptase Kit (Invitrogen, CA, USA) and 2X SG Fast qPCR Master Mix on the LightCycler480 II Real-time PCR System (Roche, Rotkreuz, Switzerland) according to the instruction supplied by the manufacturer. The expression level of IncRNA was normalized to that of $\beta$-actin, and data were analyzed according to the comparative cycle threshold $(\mathrm{CT})$ method $\left(2^{-\Delta \Delta C T}\right)$. The sequences of the primers for lncRNAs were listed in Additional file 1: Table S1. 


\section{Publicly available transcriptomic data analysis}

The expression level of AP000253 in liver tissues from $\mathrm{CHB}$ patients was reviewed in the Gene Expression Omnibus database. Consequently, the hepatic transcription profile of $59 \mathrm{CHB}$ patients (ALT > 40 and HBV DNA: positive) and 6 healthy controls from GSE83148 dataset (Affymetrix Human Genome U133 Plus 2.0 Array) was downloaded for the following analysis. Data was preprocessed with limma package in $\mathrm{R}$ language. FDR (false discovery rate) $<0.05$ and $\left|\log _{2} \mathrm{FC}\right|>1$ (FC, Fold change) was considered statistically significant.

\section{Cell culture, plasmids and transfection}

Human hepatoma cell lines Huh7, HepG2 and HepG2.2.15 were purchased from the Cell Resource Center (IBMS, China). All cells were cultured in DMEM (Gibco, USA) with 10\% FBS (Hyclone, USA), $100 \mathrm{U} /$ $\mathrm{ml}$ penicillin and $100 \mu \mathrm{g} / \mathrm{ml}$ streptomycin and maintained in a humidified atmosphere at $37{ }^{\circ} \mathrm{C}$ with $5 \%$ CO2. The pHBV1.3 plasmid containing 1.3 copies of the HBV genome was purchased from Fenghui Biological Co., Ltd (Changsha, China). The full-length AP000253 (pcDNA3.1/AP000253), short interferon RNA (siRNA) targeting AP000253 (si-AP000253) and non-targeting siRNA (si-NC) were synthesized, constructed and purchased from Genecreate Biological Co., Ltd (Wuhan, China). Transfection was conducted with Lipofectamine 2000 reagent (Invitrogen, CA, USA) according to the manufacturer's protocols. Forty-eight hours after transfection, the cells were harvested to detect the lncRNA expression.

\section{HBV DNA, HBsAg and HBeAg detection}

Cell culture medium were collected at $72 \mathrm{~h}$ after transfection and centrifuged at $2500 \mathrm{rpm}$ for $5 \mathrm{~min}$ before the following detection. The HBV DNA in the supernatants were extracted and quantified using a diagnostic kit for quantification of HBV DNA (Kehua, Shanghai, China) on Bio-rad Real-Time PCR detection system according to the manufacturer's instructions. While HBsAg and $\mathrm{HBeAg}$ were detected with a commercial enzyme-linked immunosorbent assay (ELISA) kit (Wantai, Beijing, China).

\section{Data analysis}

All statistical analyses were performed with GraphPad Prism 5 (GraphPad Software, Inc., San Diego, USA). Continuous variables were expressed as means $\pm S D$, while categorical data was presented as counts and percentages. Student's $t$ test or $\chi^{2}$ test was used to compare the differences between two groups for continuous or categorical variables accordingly. The relationships between AP00253 and clinical parameters were assessed by Pearson's correlation coefficient analysis. Additionally, receiver-operating characteristic (ROC) curve was performed to evaluate the diagnostic performance of AP00253 for OBI. A value of $P<0.05$ was considered statistically significant.

\section{Results}

\section{Demographics of study population}

The detailed clinical information for all subjects was presented in Table 1. Similar demographics were found among these groups. OBI patients were mainly middleaged men. Of 34 OBI with complete serological results, 30 OBI were "seropositive OBI" including 28 Anti-HBc positive and 7 Anti-HBs positive. In addition, compared with ASC group, the viral load was lower in OBI.

\section{Expression of $15 \mathrm{HBV}$ infection-related IncRNAs}

\section{in discovery phase}

The plasma level of $15 \mathrm{HBV}$ infection-related lncRNAs in $10 \mathrm{OBI}$ and $10 \mathrm{HCs}$ were measured with qRT-PCR assay. As Fig. 1 displayed, HOTAIR, LINC00994, AL355102.1, HULC and AP000253 were significantly down-regulated, while DHRS was up-regulated in OBI when compared to HCs $(F C>2)$. No significant differences were observed in the level of HNF4A-AS1, AC092168.1, AC022898.1 and AL160408.1. Moreover, the remaining 5 lncRNAs, namely HCP5, MALAT1, HEIH, DREH and T262735, failed to be detected in plasma. Collectively, except DHRS because of low expression level, HOTAIR, LINC00994, AL355102.1, HULC and AP000253 were selected as candidate lncRNAs for further validation.

\section{Validation of 5 candidate IncRNAs in plasma by qRT-PCR}

Then, the plasma level of 5 candidate lncRNAs were further validated in independent cohorts including $20 \mathrm{HCs}$, 64 OBI, $31 \mathrm{CHB}$ and 20 ASC. As shown in Fig. 2. The level of AP000253 was significantly lower in OBI, ASC and $\mathrm{CHB}$ groups compared with $\mathrm{HCs}$ group, and gradually increased from $\mathrm{CHB}$ to OBI, ASC and HCs, despite no significant difference was found among OBI, ASC and CHB $(P>0.05)$. Additionally, the level of LINC00994 was also lower in ASC than in HCs group. When compared to OBI, the lower level of HOTAIR in ASC and CHB groups was observed. Beside these differences, the level of these 5 lncRNAs was not significantly altered between other two groups.

\section{Associations between plasma AP000253 and clinical characteristics}

The associations between the expression level of AP000253 and clinical characteristics were further 
Table 1 Baseline characteristics of the subjects in study

\begin{tabular}{|c|c|c|c|c|c|c|c|c|}
\hline & \multicolumn{3}{|c|}{ Discovery phase } & \multicolumn{5}{|c|}{ Validation phase } \\
\hline & $\mathrm{HCs}(n=10)$ & $\mathrm{OBI}(n=10)$ & $P$ & $\mathrm{HCs}(n=20)$ & $\mathrm{OBI}(\mathrm{n}=64)^{\mathrm{a}}$ & $\operatorname{ASC}(n=20)$ & $\mathrm{CHB}(\mathrm{n}=31)^{\mathrm{b}}$ & $P$ \\
\hline \multicolumn{9}{|l|}{ Demographic characteristics } \\
\hline Female $(n, \%)$ & $1(10.00)$ & $2(20.00)$ & 0.53 & $6(30.00)$ & $22(34.38)$ & $7(35.00)$ & $10(41.94)$ & 0.98 \\
\hline Age (years) & $39.30 \pm 11.68$ & $42.80 \pm 7.96$ & 0.45 & $38.00 \pm 7.94$ & $42.86 \pm 8.81$ & $36.00 \pm 7.48$ & $43.11 \pm 14.16$ & 0.09 \\
\hline \multicolumn{9}{|l|}{ Serological characteristics } \\
\hline $\operatorname{ALT}(U / L)$ & $19.56 \pm 7.63$ & $22.70 .67 \pm 11.14$ & 0.48 & $16.74 \pm 6.41$ & $18.99 \pm 9.79$ & $37.80 \pm 8.23$ & $219.94 \pm 263.70$ & 0.13 \\
\hline HBsAg (S/CO, positive) & $\begin{array}{l}0.31 \pm 0.30 \\
0\end{array}$ & $\begin{array}{l}0.12 \pm 0.16 \\
0\end{array}$ & 0.12 & $\begin{array}{l}0.21 \pm 0.25 \\
0\end{array}$ & $\begin{array}{l}0.16 \pm 0.21 \\
0\end{array}$ & $\begin{array}{l}22.89 \pm 9.91 \\
20\end{array}$ & $\begin{array}{l}272.28 \pm 139.62 \\
31\end{array}$ & $<0.01^{c}$ \\
\hline Anti-HBs (S/CO, positive) & $\begin{array}{l}7.00 \pm 8.32 \\
5\end{array}$ & $\begin{array}{l}0.87 \pm 0.72 \\
3\end{array}$ & 0.04 & $\begin{array}{l}8.24 \pm 8.18 \\
12\end{array}$ & $\begin{array}{l}0.77 \pm 1.21 \\
7\end{array}$ & $\begin{array}{l}0.21 \pm 0.24 \\
0\end{array}$ & $\begin{array}{l}0.23 \pm 0.72 \\
0\end{array}$ & $<0.01^{c}$ \\
\hline HBeAg (S/CO, positive) & $\begin{array}{l}0.08 \pm 0.03 \\
0\end{array}$ & $\begin{array}{l}0.07 \pm 0.02 \\
0\end{array}$ & 0.89 & $\begin{array}{l}0.07 \pm 0.01 \\
0\end{array}$ & $\begin{array}{l}0.05 \pm 0.02 \\
0\end{array}$ & $\begin{array}{l}0.06 \pm 0.01 \\
0\end{array}$ & $\begin{array}{l}38.91 \pm 82.97 \\
7\end{array}$ & $0.46^{c}$ \\
\hline Anti-HBe (S/CO, positive) & $\begin{array}{l}1.60 \pm 0.31 \\
0\end{array}$ & $\begin{array}{l}1.28 \pm 0.47 \\
2\end{array}$ & 0.11 & $\begin{array}{l}1.88 \pm 0.12 \\
0\end{array}$ & $\begin{array}{l}0.97 \pm 0.40 \\
8\end{array}$ & $\begin{array}{l}0.24 \pm 0.34 \\
19\end{array}$ & $\begin{array}{l}8.53 \pm 30.90 \\
24\end{array}$ & $<0.01^{c}$ \\
\hline Anti-HBC (S/CO, positive) & $\begin{array}{l}1.48 \pm 0.47 \\
1\end{array}$ & $\begin{array}{l}0.71 \pm 0.73 \\
7\end{array}$ & 0.02 & $\begin{array}{l}1.96 \pm 0.40 \\
0\end{array}$ & $\begin{array}{l}0.45 \pm 0.53 \\
28\end{array}$ & $\begin{array}{l}0.08 \pm 0.07 \\
20\end{array}$ & $\begin{array}{l}11.03 \pm 1.84 \\
31\end{array}$ & $<0.01^{\mathrm{C}}$ \\
\hline HBV-DNA (Ct) & NA & $34.89 \pm 1.25$ & NA & NA & $35.86 \pm 1.87$ & $33.67 \pm 3.01$ & $23 \sim 2.88 \mathrm{E}+8$ & $<0.01^{c}$ \\
\hline
\end{tabular}

$O B I$ occult HBV infection, $C H B$ chronic hepatitis $B, A S C$ asymptomatic HBsAg carriers, $H C$ healthy controls, $H B s A g$ hepatitis $B$ surface antigen, $A$ nti-HBs antibody for $\mathrm{HBsAg}, \mathrm{HBeAg}$ hepatitis B envelope antigen, Anti-HBe antibody for $\mathrm{HBeAg}$, Anti-HBc antibody for hepatitis B core antigen, ALT alanine aminotransferase, $\mathrm{Ct}$ cycle threshold, NA not available

${ }^{a}$ Due to limited volume, the results of Anti-HBs, HBeAg, Anti-HBe and Anti-HBc were only available for 34 OBI samples

${ }^{b} \mathrm{HBsAg}$, Anti-HBs, HBeAg, Anti-HBe and Anti-HBc were measured with Anytest-2000 TRF detection system, and HBV DNA was detected with HBV DNA PCRfluorescence quantitative diagnostic kit(KHB)

c $P$ value indicated the statistic differences between $\mathrm{HCs}, \mathrm{OBI}$ and $\mathrm{ASC}$ groups

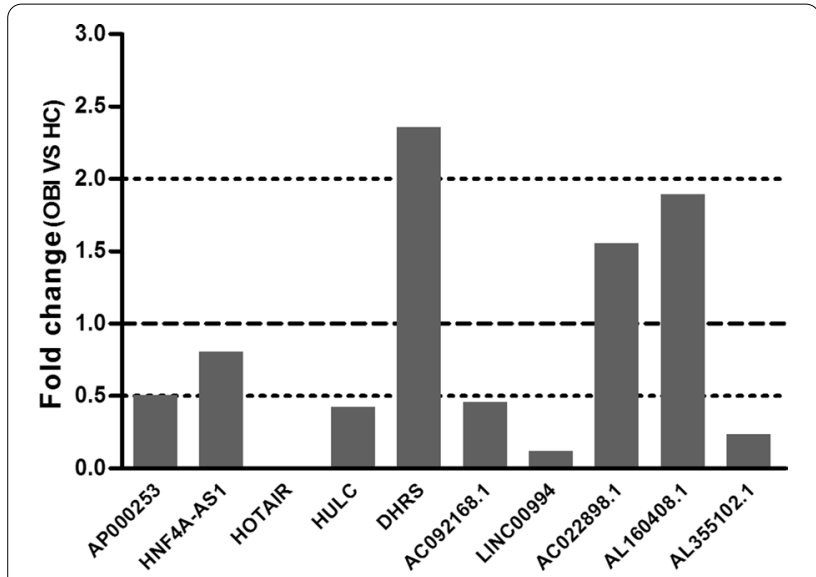

Fig. 1 The expression level of plasma IncRNAs between OBI and $\mathrm{HCs}$ in the discovery cohorts. The fold change (FC) of OBI versus $\mathrm{HC}$ represented the ratio of the mean of target IncRNA expression between $\mathrm{OBI}$ and $\mathrm{HCs}$ groups. The expression level of IncRNAs was relative to $\beta$-actin. $F C$ value $\leq 0.5$ : downregulated; $F C$ value $\geq 2.0$ : upregulated; $0.5<F C$ value < 2.0: no changes. $O B /$ occult HBV infection, HCs healthy controls

explored and no significant association with sex, age, the serum level of ALT and serologic viral markers, including
HBs-Ab, HBe-Ab, HBc-Ab and HBV-DNA, was observed in OBI group (Fig. 3A). Meanwhile, no significant association was also found between plasma AP000253 and age and the serum level of ALT, HBV-DNA or HBsAg in ASC (Fig. 3B) and CHB groups (Fig. 3C). Moreover, the detail results of correlation analysis between plasma AP000253 and serologic viral characteristics of patients with HBV infection were summarized in Additional file 2: Table S2.

\section{Diagnostic performance of plasma AP000253 for OBI}

Subsequently, the diagnostic value of plasma AP000253 for OBI was evaluated. The ROC curve analysis demonstrated that AP000253 was useful in differentiating OBI from $\mathrm{HCs}$ with an AUC of 0.73 , at a cutoff value of -0.84 for AP000253 expression level $(\Delta C T)$, the optimal sensitivity and specificity were $60 \%$ and $75 \%$, respectively. Comparable differentiation power between patients with HBV infection and HCs was also achieved with the AUC of 0.74. At the cutoff value of 1.175 for AP000253 expression level $(\Delta C T)$, the optimal sensitivity and specificity were $53.45 \%$ and $85 \%$, respectively. However, AP000253 failed to differentiate OBI from ASC or CHB patients (Fig. 4). 

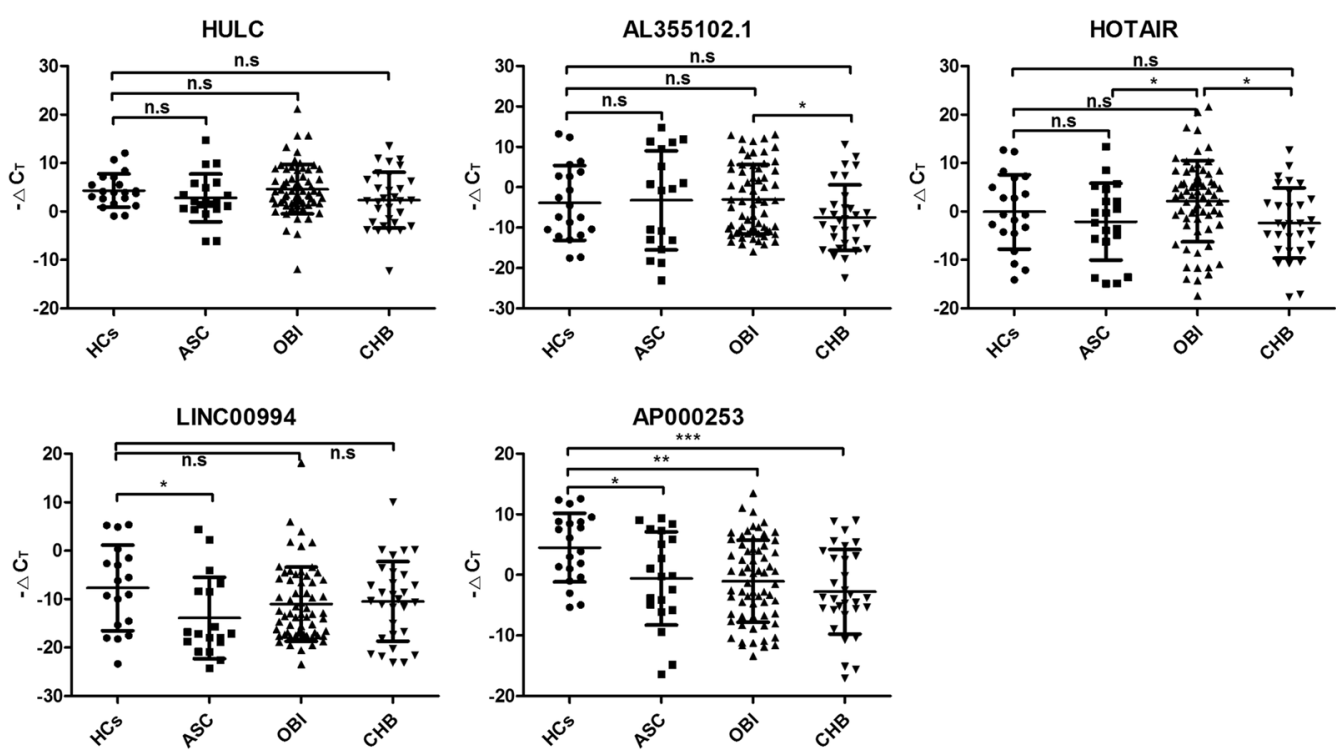

Fig. 2 The expression level of 5 candidate IncRNAs in plasma among study subjects in the validation cohorts. The relative expression of IncRNA was reported as $\triangle C T$, which was calculated by subtracting the $C T$ (cycle threshold) of $\beta$-actin from the $C T$ of target IncRNAs. OBI occult HBV infection, CHB chronic hepatitis B, ASC asymptomatic HBsAg carriers, HCs healthy controls; ${ }^{* *} P<0.001$; ${ }^{* *} P<0.01$; ${ }^{*} P<0.05$, n.s. not significant

\section{IncRNA AP000253 expression in liver tissues and human hepatoma cell lines}

According to the GSE83148 dataset, we found that the level of AP000253 was also significantly lower in liver tissues with $\mathrm{CHB}$ compared to normal liver tissues $\left(\log _{2} \mathrm{FC}=-1.44, \mathrm{FDR}=0.0001\right.$, Fig. $5 \mathrm{~A}$ and Additional file 3: Table S3), consistent with that in plasma. However, unexpectedly, the level of AP00253 was higher in HBV-expressing hepatoma cell lines, despite the difference did not reach statistical significance in Huh7/ pHBV1.3 cell line (Fig. 5B).

\section{IncRNA AP000253 promoted HBV replication in human hepatoma cell lines}

Finally, to gain further insight into the biological roles of AP000253 in HBV infection, AP000253 over-expression plasmid (pcDNA3.1/AP000253) and knockdown plasmid (si-AP000253) were generated and transfected into Huh7/pHBV1.3 and HepG2.2.15 cells. The overexpression and knockdown efficiency of AP000253 was further confirmed by qRT-PCR (Fig. 5C). As the results demonstrated, ELISA and qPCR assays indicated that HBV DNA, HBsAg and HBeAg increased in the supernatant of AP000253-overexpressing cells and reduced in AP000253-knockdown cells at $72 \mathrm{~h}$ after transfection (Fig. 5D, E). These results suggested that AP000253 might facilitate the HBV transcription and replication.

\section{Discussion}

The existence of OBI makes the management of HBV infection more difficult, and is a serious threat to the transfusion safety $[8,9]$. To improve the screening and a better understanding of the pathogenesis of $\mathrm{OBI}$ is therefore desirable [1, 4, 6, 29]. Recent studies have identified many lncRNAs associated with HBV infection, and an understanding of their functional roles in the pathogenesis of HBV infectious diseases is just emerging [20, 21]. However, the lncRNA expression in OBI is still unclear.

In the present study, among $15 \mathrm{HBV}$ infection-related lncRNAs, only plasma AP000253 was consistently differently expressed between OBI and HCs. Despite there was a rising trend from $\mathrm{CHB}$ to $\mathrm{OBI}, \mathrm{ASC}$ and $\mathrm{HCs}$, no significant difference in plasma level of AP000253 was found among OBI, ASC and CHB groups. Subsequently, We respectively evaluated the correlation between plasma AP000253 and clinical characteristics in OBI, ASC and $\mathrm{CHB}$ groups, and no association with demographic characteristics or serologic viral biomarkers such as antigen, antibody and nucleic acid, was found, which indicated that plasma AP000253 might serve as an independent biomarker of infection regardless of the progression status of HBV infection. Unfortunately, due to the scarcity and limited volume of OBI samples, the associations between AP000253 and overall clinical parameters could not be systematically and comprehensively assessed. 

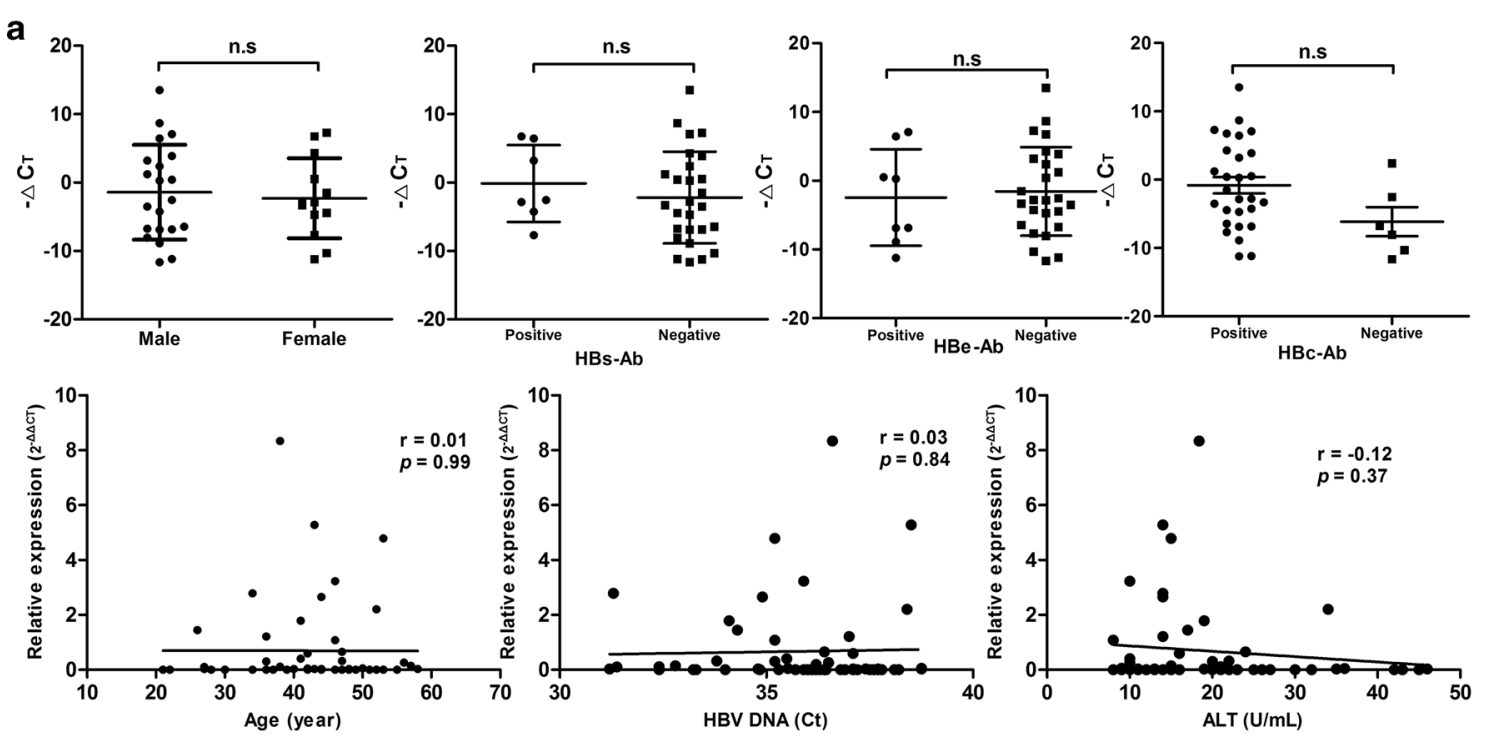

b
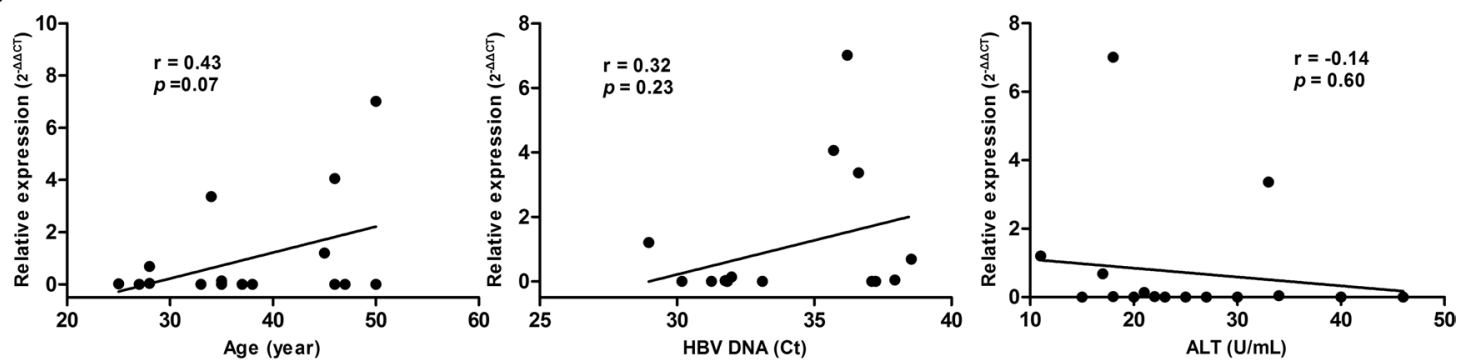

C
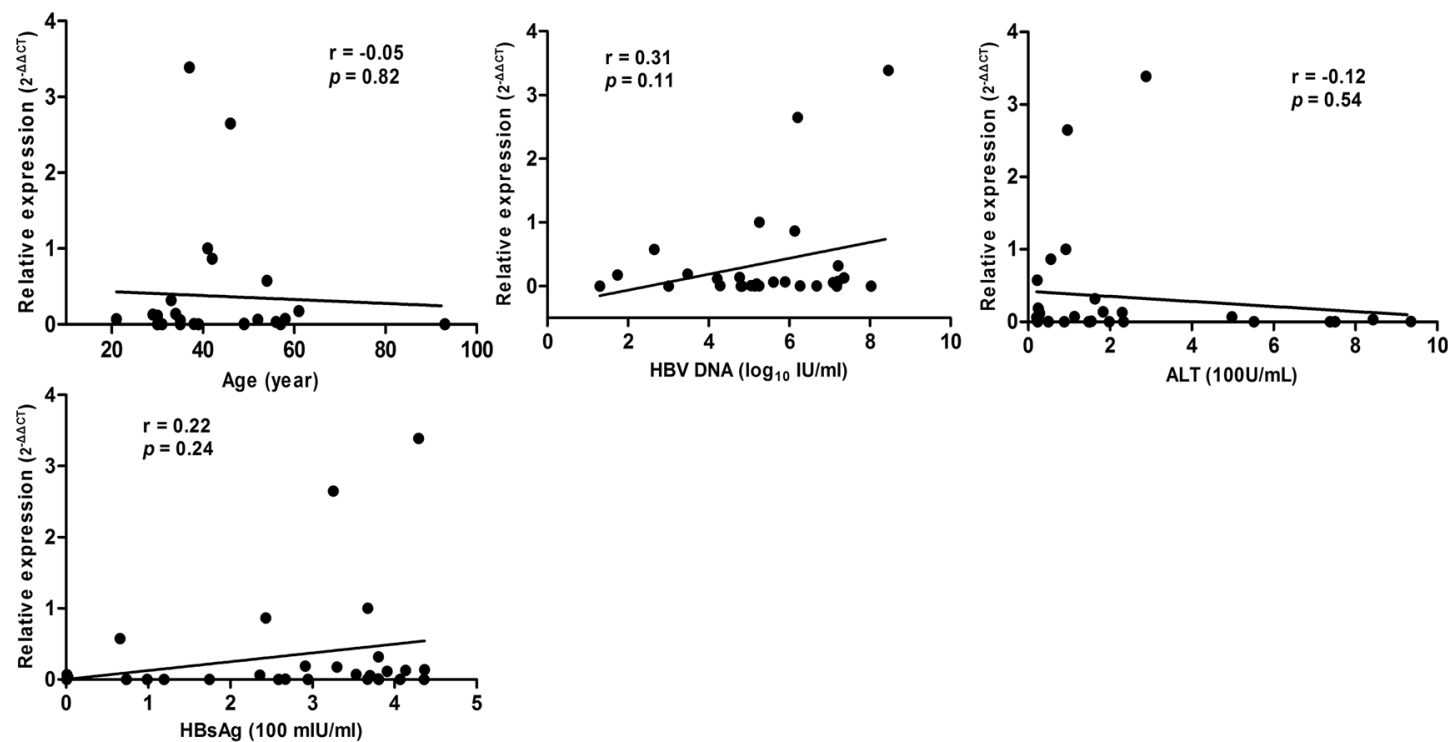

Fig. 3 Correlations between plasma AP000253 and clinical characteristics of patients with HBV infection. Correlations between plasma AP000253 and sex, HBs-Ab, HBe-Ab, HBC-Ab, age, HBV DNA and ALT in OBI group (A); Correlations between plasma AP000253 and age, HBV DNA and ALT in ASC group (B); and correlations between plasma AP000253 and age, HBV DNA, ALT and HBsAg in CHB group (C). The correlation co-efficiency ( $r$ ) and the two-tailed $P$ values were evaluated with Pearson's test. OBI occult HBV infection, CHB chronic hepatitis B, ASC asymptomatic HBsAg carriers, ALT alanine aminotransferase, Ct cycle threshold 


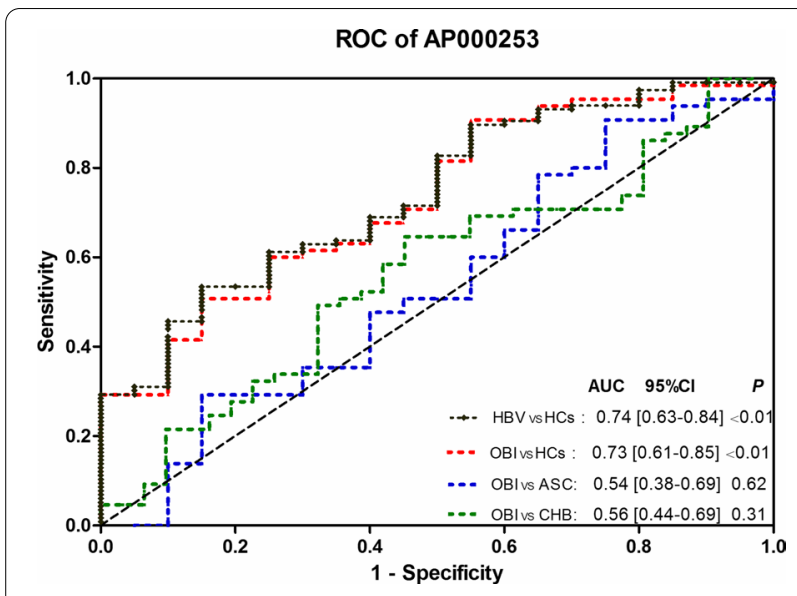

Fig. 4 Receiver operating characteristic (ROC) curve analysis for discriminative ability among $\mathrm{OBI}, \mathrm{ASC}, \mathrm{CHB}$ and $\mathrm{HCs}$ by plasma AP000253 in the validation cohorts. OBI occult HBV infection, $C H B$ chronic hepatitis B, ASC asymptomatic HBsAg carriers, HBV patients with HBV infection, HCs healthy controls, AUC the area under the ROC curve

Currently, the gold standard for the diagnosis of OBI was based on the detection of replication-competent viral DNA (i.e. cccDNA and rcDNA), not the presence of integrated viral DNA fragment in the liver [31-33]. Regrettably, a standardized assay with internal and external validity is still nonexistent yet. In clinical practice, due to the always unavailable liver tissues, the diagnosis of OBI is commonly based on the detection of HBV DNA in the blood instead. While, unfortunately, because of limited sensitivity of the existing commercial assays, $\mathrm{OBI}$ is often missed [5]. As reported, to prevent HBV transmission by transfusion, the sensitivity of nucleic acid assays would need to be lowered from the current $3.4 \mathrm{IU} / \mathrm{ml}$ to a new lower limit of detection of $0.15 \mathrm{IU} / \mathrm{ml}$ [6]. Hence, to identify novel biomarkers or approaches to improve the OBI screening is urgent. Recently, increasing evidence has demonstrated that lncRNAs had great potential as a diagnostic biomarker for many diseases [34, 35]. Then, the potential of AP000253 as a novel blood-based biomarker in OBI screening was evaluated. Consequently, plasma AP000253 could moderately differentiate OBI from HCs, but fail to discriminate OBI from ASC as well as CHB. When differentiating patients with $\mathrm{HBV}$ infection from HCs, similar performance was also observed. These results suggested that AP000253 might be useful in identifying patients with $\mathrm{HBV}$ infection, but fail to specifically separate the stage of chronic HBV infection. In the setting of blood donations, in order to reduce the residual risk of transfusion-transmitted HBV infection, the screening strategy adopted by Chinese blood centers is as following: (1) HBsAg rapid screening test in pre-donation, (2) if nonreactive (HBsAg negative), and then two rounds of HBsAg screening with different ELISA assays combined with nucleic acid testing in post-donation [36, 37]. In our blood center, only when HBsAg screening is nonreactive, nucleic acid testing for HBV DNA is available. Hence, in this circumstance, plasma AP000253 would be more useful and practical in discriminating OBI from $\mathrm{HCs}$ in HBsAg-negative populations, despite the diagnostic performance is moderate.

Like miRNAs, the IncRNA secretion may be also a selective process, and the peripheral blood level of lncRNAs is not always a true reflection of the intracellular level [38]. Therefore, we further investigated the AP000253 expression in liver tissues with CHB instead, because of the liver tissues with OBI were unavailable. Similarly, in the public GSE81348 dataset, the level of AP000253 was also significantly decreased. However, in HepG2.2.15 and HBV-transfected Huh7 cell lines, the expression level was opposite. One possible explanation for this discrepancy might be the interference of interstitial cells in liver tissue. Regrettably, owing to the limited resources of the liver tissues from $\mathrm{CHB}$ patients and healthy people, we failed to further experimentally confirm the AP000253 expression in liver tissues, which deserve further confirmation, especially in liver tissues with OBI.

Finally, accumulating evidence has indicated that lncRNAs can participate in diverse physiological and pathological processes and affect disparate cellular functions [11]. To the best of our knowledge, this is the first report to elaborate AP000253. AP000253 (LOC102724449), a neighbor lncRNA gene of human SOD1 gene, is located at chromosome 21q22.11 with a length of $4282 \mathrm{bp}$, containing three exons. According to the RNA-Seq expression data from GTEx database, AP000253 shows tissue-specific distributions, and is highly expressed in the liver and testis. Moreover, it has no coding probabilities predicted by the Coding Potential Calculator. The subcellular localization of lncRNAs always determines their possible mechanisms. From the lncLocator database, AP000253 transcript (XR_430363.3) is predominantly located in cytoplasm, suggesting that it may exert biological functions at post-transcriptional level. Due to the cell or animal models of OBI are not available, we then try to preliminarily explore the possible biological functions of AP000253 using HepG2.2.15 and HBV-transfected Huh7 cell lines. ELISA and qPCR assays indicated that AP000253 could significantly enhance the levels of HBsAg, HBeAg and HBV DNA, suggesting that AP000253 might be able to modulate HBV transcription and replication in hepatoma cells. However, the molecular mechanisms of AP000253 in modulating HBV replication need to be further clarified, which is what we are now working on. 

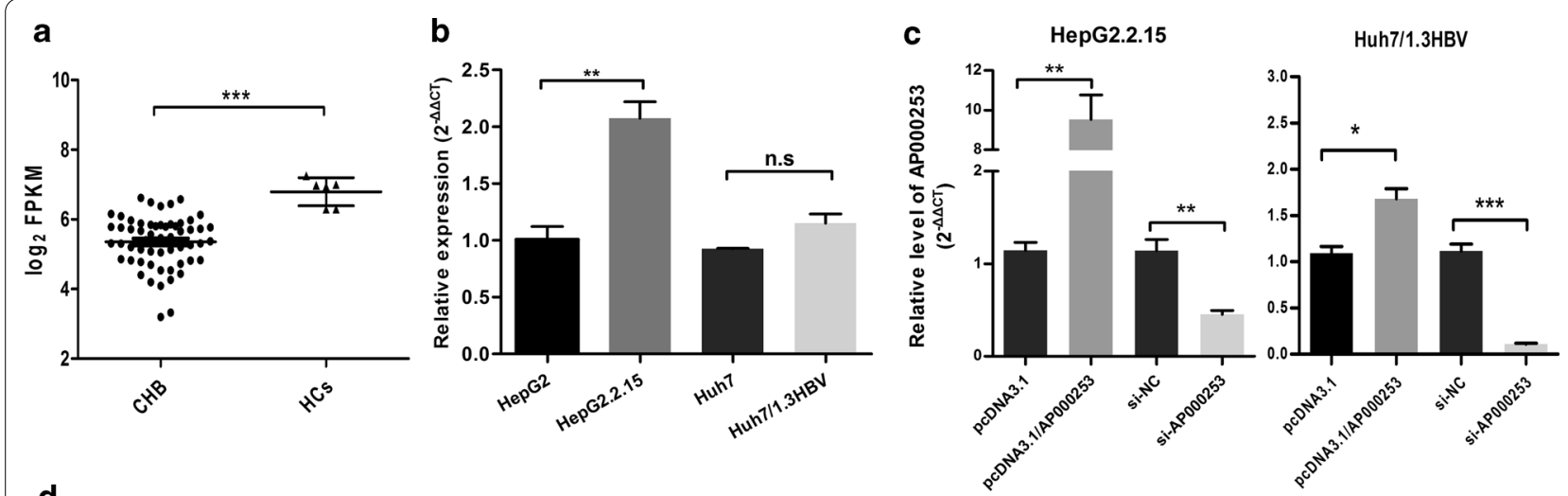

d
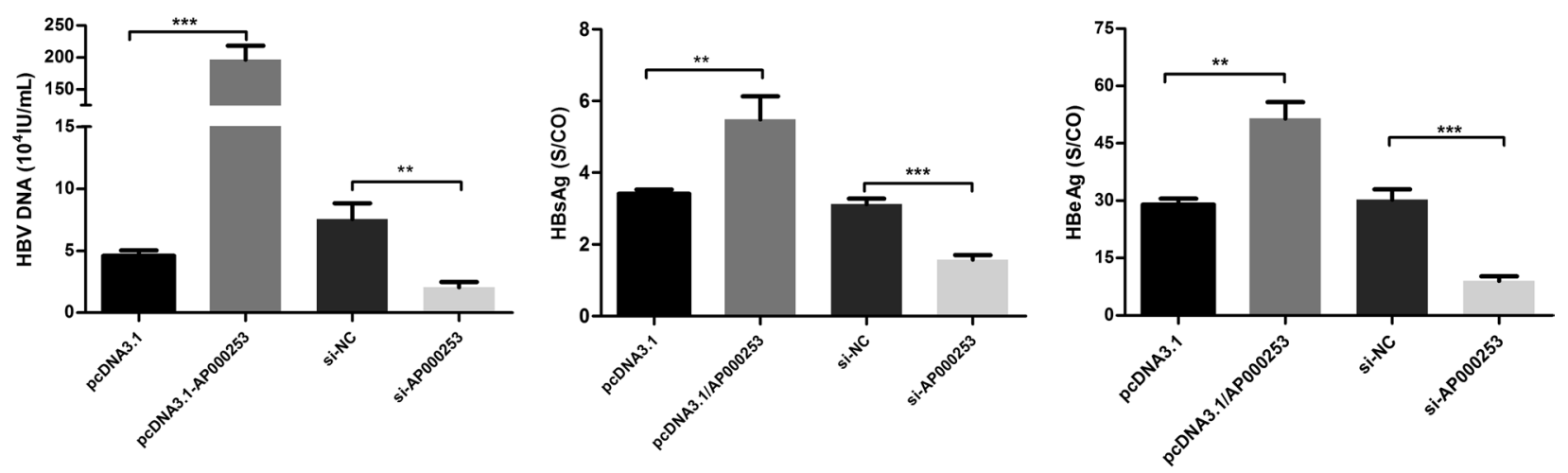

e
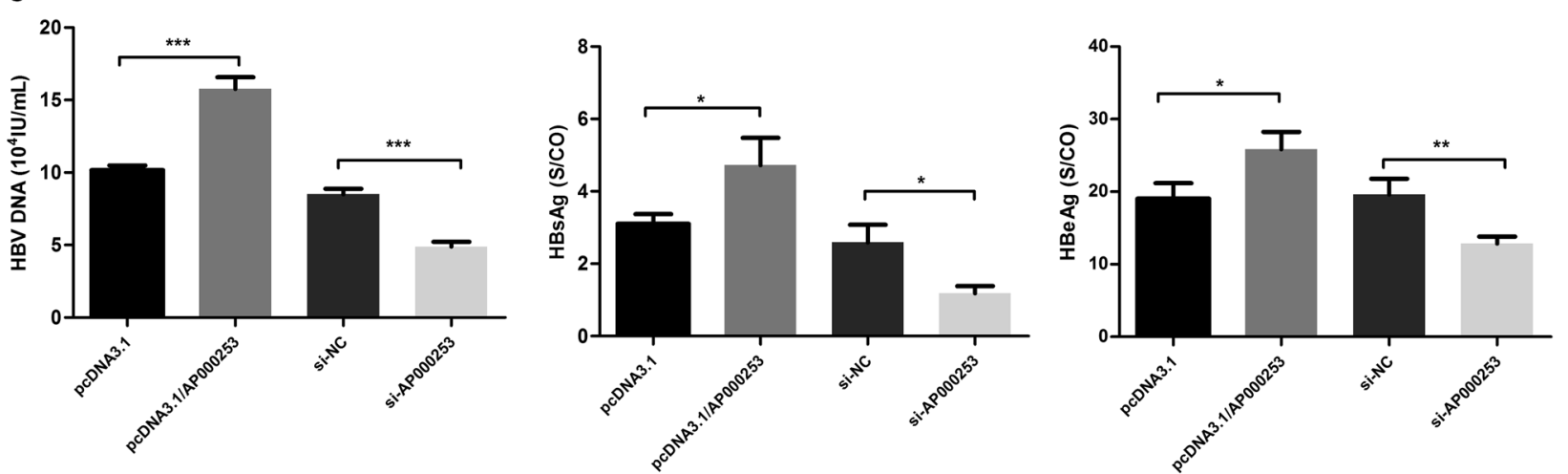

Fig. 5 IncRNA AP000253 promoted HBV transcription and replication. (A) The relative level of AP00253 was determined by microarray in liver tissues of CHB ( $n=59)$ and healthy controls $(n=6)$ from the GSE83148 dataset; (B) The level of AP00253 was detected by qRT-PCR in HepG2, HepG2.2.15, Huh7 and Huh7/pHBV1.3 cells; (C) Validation of overexpression and knockdown efficiency of AP000253 in both HepG2.2.15 and Huh7/ pHBV1.3 cells by qRT-PCR, respectively; (D) The levels of HBV DNA, HBSAg and HBeAg were measured by qPCR or ELISA assays in the supernatant of HepG2.2.15 cells treated with si-NC or si-IncRNA AP000253 and pcDNA3.1 or pcDNA3.1/IncRNA AP000253 for 3 days, respectively; (E) The levels of HBV DNA, HBsAg and HBeAg were measured by qPCR or ELISA assays in the supernatant of Huh7/pHBV1.3 cells treated with si-NC or si-IncRNA AP000253 and pcDNA3.1 or pcDNA3.1/IncRNA AP000253 for 3 days, respectively; CHB chronic hepatitis B, HCs healthy controls; ${ }^{* * *} P<0.001$; **P $<0.01 ; * P<0.05$, n.s. not significant

\section{Conclusion}

In conclusion, we report that AP000253 might promoted HBV transcription and replication, and decreased level of AP000253 was observed in plasma of OBI, ACS and CHB patients. In the setting of blood donations, AP000253 might be more useful as a biomarker of HBV infection to moderately distinguish OBI from HCs in HBsAg-negative donors. However, the AP000253 expression in liver tissues and AP000253-associated molecular pathological mechanism in HBV infection should be further explored in future. 


\section{Abbreviations}

IncRNAs: Long noncoding RNAs; OBI: Occult HBV infection; CHB: Chronic hepatitis B; ASC: Asymptomatic HBsAg carriers; HBV: Hepatitis B virus; HCs: Healthy controls; GEO: Gene Expression Omnibus database; qRT-PCR: Realtime quantitative RT-polymerase chain reaction; HBsAg: Hepatitis B surface antigen; Anti-HBs: Antibody for HBsAg; HBeAg: Hepatitis B envelope antigen; Anti-HBe: Antibody for HBeAg; Anti-HBc: Antibody for Hepatitis B core antigen; ALT: Alanine aminotransferase; Ct: Cycle threshold

\section{Supplementary Information}

The online version contains supplementary material available at https://doi. org/10.1186/s12985-021-01596-y.

Additional file 1. Table S1. Primers used for quantitative PCR of IncRNAs

Additional file 2. Table S2. Correlations between plasma AP000253 and clinical parameters in the validation cohorts.

Additional file 3. Table S3. The characteristic of differentially expressed AP00253 in chronic hepatitis B from the GSE83148 dataset.

\section{Acknowledgements}

Not applicable.

\section{Authors' contributions}

Conceptualization: QH, WX, JJ and ZL. Experiments and data curation: QH, ZW, QW and BC. Formal analysis: QH, ZW, WX and ZL. Software: XL. Resources: JJ. Writing_original draft: QH and ZL. Writing_review \& editing: QW, WX, HC, HQ and ZL. All authors read and approved the final manuscript.

\section{Funding}

This study is funded by the science foundation of science and technology department (No. WX18IIAN037), health commission of Wuxi (No. MS201925), and the top talent support program for young and middle-aged people of Wuxi healthy committee (HB2020101).

\section{Availability of data and materials}

The data and material generated or analyzed in this study are available upon reasonable request, and could be provided by Zhonghua Lu (Lu_z_h1@126. com) or Wei Xia (xiawe25@126.com).

\section{Declarations}

\section{Ethics approval and consent to participate}

This study was conducted in accordance with the Declaration of Helsinki and was approved by the Ethics Committee of Wuxi Red Cross Blood Center. Written informed consent was obtained from all participants.

\section{Consent for publication}

All authors have agreed on the consent of the manuscript.

\section{Competing interests}

The authors declare that there is no conflict of interest.

Received: 25 March 2021 Accepted: 4 June 2021

Published online: 10 June 2021

\section{References}

1. Raimondo G, Locarnini S, Pollicino T, et al. Update of the statements on biology and clinical impact of occult hepatitis b virus infection. J Hepatol. 2019;71(2):397-408

2. Raimondo G, Allain JP, Brunetto MR, et al. Statements from the Taormina expert meeting on occult hepatitis B virus infection. J Hepatol. 2008;49(4):652-7.

3. Samal J, Kandpal M, Vivekanandan P. Molecular mechanisms underlying occult hepatitis B virus infection. Clin Microbiol Rev. 2012;25(1):142-63.
4. Mak LY, Ka-Ho Wong D, Pollicino T, Raimondo G, Hollinger FB, Yuen MF. Occult hepatitis B infection and hepatocellular carcinoma: epidemiology, virology, hepatocarcinogenesis and clinical significance. J Hepatol. 2020;73(4):952-64.

5. Shyamala V. Nucleic Acid Technology (NAT) testing for blood screening: impact of individual donation and Mini Pool_NAT testing on analytical sensitivity, screening sensitivity and clinical sensitivity. ISBT Sci Ser. 2014;9(2):315-24

6. Candotti D, Assennato SM, Laperche S, Allain JP, Levicnik-Stezinar S. Multiple HBV transfusion transmissions from undetected occult infections: revising the minimal infectious dose. Gut. 2018;68(2):313-21.

7. Seed CR, Allain JP, Lozano M, et al. International forum on Occult hepatitis B infection and transfusion safety. Vox Sang. 2019;114(4):397-406.

8. Yip TC, Wong GL. Current knowledge of occult hepatitis B infection and clinical implications. Semin Liver Dis. 2019;39(2):249-60.

9. Malagnino V, Fofana DB, Lacombe K, Gozlan J. Occult hepatitis B virus infection: an old entity with novel clinical involvements. Open Forum Infect Dis. 2018;5(10):ofy227.

10. Derrien $T$, Johnson R, Bussotti G, et al. The GENCODE v7 catalog of human long noncoding RNAs: analysis of their gene structure, evolution, and expression. Genome Res. 2012;22(9):1775-89.

11. Kopp F, Mendell JT. Functional classification and experimental dissection of long noncoding RNAs. Cell. 2018;172(3):393-407.

12. Agliano F, Rathinam VA, Medvedev AE, Vanaja SK, Vella AT. Long noncoding RNAs in host-pathogen interactions. Trends Immunol. 2019;40(6):492-510

13. Ray RM, Morris KV. Long non-coding RNAs mechanisms of action in HIV-1 modulation and the identification of novel therapeutic targets. Noncoding RNA. 2020;6(1):12

14. Liu S, Liu X, Li J, et al. Long noncoding RNAs: novel regulators of virushost interactions. Rev Med Virol. 2019;29(4):e2046.

15. Yilmaz Susluer S, Kayabasi C, Ozmen Yelken B, et al. Analysis of long noncoding RNA (IncRNA) expression in hepatitis B patients. Bosn J Basic Med Sci. 2018;18(2):150-61.

16. Chen W, Lin C, Gong L, et al. Comprehensive analysis of the mRNAIncRNA co-expression profile and ceRNA networks patterns in chronic hepatitis B. Curr Genom. 2019;20(4):231-45.

17. Zeng Y, Wu W, Fu Y, et al. Toll-like receptors, long non-coding RNA NEAT1, and RIG-I expression are associated with HBeAg-positive chronic hepatitis B patients in the active phase. J Clin Lab Anal. 2019:33(5):e22886.

18. Hao Q, Wang Z, Wang Q, et al. Differential expression profile of long noncoding RNAs in chronic HBV infection: new insights into pathogenesis. J Med Virol. 2020;92(12):3390-402.

19. Ruan $L$, Huang $L$, Zhao $L$, et al. The Interaction of IncRNA-HEIH and IncRNA-HULC with HBXIP in Hepatitis B Patients. Gastroenterol Res Pract. 2018;2018:9187316

20. Liu Y, Feng J, Sun M, et al. Long non-coding RNA HULC activates HBV by modulating HBX/STAT3/miR-539/APOBEC3B signaling in HBV-related hepatocellular carcinoma. Cancer Lett. 2019;454:158-70.

21. Feng J, Yang G, Liu Y, et al. LncRNA PCNAP1 modulates hepatitis B virus replication and enhances tumor growth of liver cancer. Theranostics. 2019;9(18):5227-45

22. Zhao $X$, Fan $H$, Chen $X$, et al. HBV DNA polymerase restrains viral replication via the CREB1-HOTTIP-HOXA13 axis. Hepatology (Baltimore, MD). 2021;73(2):503-19.

23. Nishitsuji $H$, Ujino S, Yoshio S, et al. Long noncoding RNA\# 32 contributes to antiviral responses by controlling interferon-stimulated gene expression. Proc Natl Acad Sci. 2016;113(37):10388-93.

24. Ren F, Ren JH, Song CL, et al. LnCRNA HOTAIR modulates hepatitis B virus transcription and replication by enhancing SP1 transcription factor. Clin Sci (Lond). 2020;134(22):3007-22.

25. Chen Y, Li L, Zhou Z, Wang N, Zhang CY, Zen K. A pilot study of serum microRNA signatures as a novel biomarker for occult hepatitis $B$ virus infection. Med Microbiol Immunol. 2012;201(3):389-95.

26. Wang Y, Zhu P, Qiu J, et al. Identification and characterization of interferon signaling-related microRNAs in occult hepatitis B virus infection. Clin Epigenetics. 2017;9:101

27. Hao QQ, Wang QH, Xia W, Qian HZ. Circulating miRNA expression profile and bioinformatics analysis in patients with occult hepatitis B virus infection. J Med Virol. 2020;92(2):191-200. 
28. Chinese Society of Infectious Diseases CMA, Chinese Society of Hepatology CMA. The guidelines of prevention and treatment for chronic hepatitis B (2019 version). Chin J Hepatol. 2019;27(12):938-61.

29. Spreafico M, Berzuini A, Foglieni B, et al. Poor efficacy of nucleic acid testing in identifying occult HBV infection and consequences for safety of blood supply in Italy. J Hepatol. 2015;63(5):1068-76.

30. Qiu L, Wang T, Xu X, Wu Y, Tang Q, Chen K. Long non-coding RNAs in hepatitis B virus-related hepatocellular carcinoma: regulation, functions, and underlying mechanisms. Int J Mol Sci. 2017;18(12):2505.

31. Caviglia GP, Abate ML, Tandoi F, et al. Quantitation of HBV cccDNA in anti-HBC-positive liver donors by droplet digital PCR: a new tool to detect occult infection. J Hepatol. 2018;69(2):301-7.

32. Liu Y, Zeng W, Xi J, et al. Over-gap PCR amplification to identify presence of replication-competent HBV DNA from integrated HBV DNA: an updated occult HBV infection definition. J Hepatol. 2018;70(3):557-9.

33. Lai C-L, Wong D, Ip P, et al. Reduction of covalently closed circular DNA with long-term nucleos $(\mathrm{t})$ ide analogue treatment in chronic hepatitis B. J Hepatol. 2017;66(2):275-81.
34. Ramnarine VR, Kobelev M, Gibb EA, et al. The evolution of long noncoding RNA acceptance in prostate cancer initiation, progression, and its clinical utility in disease management. Eur Urol. 2019;76(5):546-59.

35. Zhang L, Meng X, Zhu XW, et al. Long non-coding RNAs in Oral squamous cell carcinoma: biologic function, mechanisms and clinical implications. Mol Cancer. 2019;18(1):102.

36. Gou H, Pan Y, Ge H, et al. Evaluation of an individual-donation nucleic acid amplification testing algorithm for detecting hepatitis B virus infection in Chinese blood donors. Transfusion. 2015;55(9):2272-81.

37. Wang L, Chang L, Xie Y, et al. What is the meaning of a nonresolved viral nucleic acid test-reactive minipool? Transfusion. 2015;55(2):395-404.

38. Matin $F$, Jeet $V$, Moya $L$, et al. A plasma biomarker panel of four microRNAs for the diagnosis of prostate cancer. Sci Rep. 2018;8(1):6653.

\section{Publisher's Note}

Springer Nature remains neutral with regard to jurisdictional claims in published maps and institutional affiliations.
Ready to submit your research? Choose BMC and benefit from:

- fast, convenient online submission

- thorough peer review by experienced researchers in your field

- rapid publication on acceptance

- support for research data, including large and complex data types

- gold Open Access which fosters wider collaboration and increased citations

- maximum visibility for your research: over $100 \mathrm{M}$ website views per year

At BMC, research is always in progress.

Learn more biomedcentral.com/submissions 